\title{
The Element of Systems in the Organisation of Local Food Development Program in Indonesia: Case Study in Trenggalek, East Java
}

\author{
Suyatno \\ Management Department, Faculty of Economic and Businesse, Universitas Pembangunan Nasional Veteran Jakarta, Jakarta, Indonesia \\ Email address: \\ suyatnosuyatno62@yahoo.com

\section{To cite this article:} \\ Suyatno. The Element of Systems in the Organisation of Local Food Development Program in Indonesia: Case Study in Trenggalek, East \\ Java. International Journal of Economic Behavior and Organization. Vol. 7, No. 2, 2019, pp. 33-42. doi: 10.11648/j.ijebo.20190702.12
}

Received: July 11, 2019; Accepted: August 9, 2019; Published: August 23, 2019

\begin{abstract}
The research focussed on The Element of Systems on Organisation of Local Food Development Program in the district of Trenggalek, East Java Province. The research problem was How the element of systems in the program of local food development? The aim of the research was to know how was the element of systems in the organization of local food development in the district of Trenggalek. The research used qualitative descriptive method. The data were collected through observation, collection and analyzation of documents, and the result of interview to the key informants in the organization of local food development program. This research used triangulation method to keep the accurateness of data. The data were obtained from observation and deep interview to the key informants involving the Head of District Legislator, the Head of the District, the related district government offices and main actors of local food development. The result of the research showed that element of the systems in the organization of local food development program were systems of planning, funding, production, communications, the coordination, facilitation, the correctional, and publication, the guidance and extension, management, and development of the whole elements of stakeholder involved. The element of systems in the organization of local food development programs are mutually bound, integrated with one another and interacted reciprocity under the policy made by District Government.
\end{abstract}

Keywords: The Element of System, Organisation, Local Food, Development, Program

\section{Introductions}

Food security is the condition of food fulfillness for the household that reflected in the affordibility of food sufficiently in number or quality averagely. Food sovereignty is the rights of state or nation outonomousely by determining the policy on food to guarantee the people needs.

To enhance the availability and security of food with nutrition, the government conducts diversification of food program based on local potential. To make the program runs successfully we should have effective and efficient organization.

To fulfil the need of the national food, the Indonesian government have done the utilization of a great variety of agricultural products. Food commodities have been adopted and put to use indonesian food localy. To meet the need of food the government requires organization that is right, vigorous, effective and efficient. In line to the paradigm of New Public Services, Dehardt and Dehardt proposed the concept of public interest that was the result of a dialogue about the distribution of values; The role of the government as service agent; mechanisms for achieving the policy of objectives by building cooperation between public organizations and non-profit, private and public needs good systems in the organization. The organizational structure is a collaboration among a leadership structure that is shared internally and externally; the basic motivation of public servants and administrators to the public service, and the desire to contribute to society. [8]

Local food development programs for the people do not seem to run smoothly. Why is the happening actually very related to how is the actual system in the organization's program of local food development?

Systems is one of important elemens in the food 
development organisation in Indonesia. Systems consists of Information/knowledge, communication, funding, and measurement systems"[11]. Stanford explains that System is one of element in organisation design. Organisation design is the whole sequence of works that results in an alignment of vision /mission, values/ operating principles, strategies, objectives, tactics, systems, structures, people, processes, culture and performance measures in order to deliver the required results in the operating context. [19]

Based on this explanation, this paper discusses the systems element of organization in the program of local food development. The problems of this research: Is how the element of the systems in the program of local food development?

The aim of this research is to know how is the systems element in the organization of local food development in the district of Trenggalek.

\section{Theory and Hypotheses}

\subsection{Organization}

Christensen et al in the book of Organization Theory and public sector, states that all institutions are organizations, but not all organizations are institutions. In practice, however, most organization will have some institutional traits" [5] Gareth Jones states" Institutional environment is the set of values and norm that govern the behaviour of a population of organizations. [12]

Organisation is a social entity directed to obtain the goal, designed as an activity systems composed and freely coordinated to the external environment. [7]

The key element of an organization is not a building or a set of policies or procedures, the organization is composed of people who are interrelated and interact among one another that displays the functions of their Essential in achieving goals. [7].

In an analysis of organizational problems, we must specify the characteristics of the organization that carried through the dimensions of the organization. Dimensions of organizations includes the structural dimension and contextual dimensions.

Daft has described internal characteristics of an organisation involves: formalization, specialization, hierarchy of authority, centralizations, professionalism, personal ratio [7]. While the contectual demension consists of size, organizational technology, the environment, the organization's goals and strategy, organization's culture. [7].

Organization is created in order to achieve the goal. So that the objective can be achieved it would require an effective and efficient organization. The organization is a tool or means that is designed to achieve a certain goal. Tom Christensen describes that organization can thus be understood as tools or instruments for achieving certain goals seen as important in society, such as raising the standard of higher education. [5]

Organizational development is a collection of change methods that try to improve organizational effectiveness and employee well-being. [18]

Public sector organizations are organizations dealing with the public sector to implement tasks associated with public interest. Public organizations have different characteristics from private organizations/private. Public organizations are organizations that deal with non-profit public sector. According to Tom Christensen public organizations have some characteristics in the context of democracy:

1) Public organizations have leaders elected by popular vote

2) Public organizations are multifunctions, they cope with partly conflicting considerations, such as political steering, control, representation and participation by affected parties, co-determination of employees, sensitivity vis-a vis user, transparency, publicity and insight into decision - making processes, predictability, equal treatment, impartiality, neutrality, quality of services, professional independence, political loyalty, efficiency and effectiveness.

3) Most public organizations do not operate within a free and competitive market even though increased independence, the forming of State Owned Companies and exposure to competition have increased the presence of the market like arrangements in many public organizations. [5]

"The public sector is justified by its primary mandate: to serve the people. One important task is to solve conflicts and problems using as few resources as possible". [5]

Organizations in the public sector are involved in shaping and enforcing rules and laws, but they also function as political, academic and professional adviser service providers and mobilizers of resources. [5]

An effective and efficient organizsation requires good design. Organanizational design is the process by which managers select and manage aspects of structure and culture so that an organization can control the activities necessary to achieve its goals. While Organizational change is the process by which organizations redesign their structures and cultures to move from their present state to some desired future state to increase their effectiveness. [12]

Hinrichs explained that the design of the organization should consider several elements that include: (1) people in the organization, (2) process which is the flow of information and workflow, (3) Systems, including system of information / knowledge, systems of communication, system of funding, and the system of measurement (4) the structure, which is the connection and configuration of roles and responsibilities, and accountability and (5) culture of shared values, assumptions and approach to cope with external adaptation and internal integration are strengthened through norms and awards. [11].

Organisation design is the whole sequence of work that results in an alignment of vision /mission, values/ operating principles, strategies, objectives, tactics, systems, structure, people, processes, culture and performance measures in order to deliver the required results in the operating context. [19] 
Laurie J. Mullins differs organisations in many important respects but organizations also share common features, and can be viewed as open systems that take inputs from the environment and through a series of activities transform or convert into outputs to achieve some objective. [13]

\subsection{Systems}

Each organization, formal and informal, will embrace a system that regulates how the organization achieve its objectives. Every organization has rules that reflects the interests of the organization. According to Stanford system is the infrastructure to carry out a process. The systems in organizational design includes financial system, information management system and Information Technology [19]. Systems in organizations closely related to the processes, people, and performance measures. A system is a set consisting of integrated parts or components that function as a whole (Indira. S, Narayana Nursing Journal). While Bertalanffy said A system is a set of units that is relating among them. [14]

According to Robbin, "Definition of the system is a collection of parts that are interconnected and interdependent arranged so as to achieve a unity. Each system is characterized by differentiation and integration. In order to maintain unity among the parts that dideferentiation and complete the entire form, each system has a reciprocal integration process. Each system requires differentiation to identify sub-units and integration to ensure that the system is not splited into separate elements [17]

Boulding explains that a system is any organized collection of parts united by prescribed interactions and designed for the accomplishment of specific goals or general purposes [22]

Open Systems thinking views organizations as being composed of a set of various interconnected sub-systems that together constitute the whole organization. The sub-systems are open to each other in terms of impact but the organization in its entirety is also to be seen as an open system in constant interaction with the larger system of which it is a part, the multifaceted macro environment. [2]

According to Laurie the systems approach to organisation has arisen. Organisations are analysed as 'systems' with a number of inter-related sub-systems. The idea is that any part of an organisation's activities affects all other parts. The systems approach encourages managers to view the organisation both as a whole and as part of a larger environment. [13]

Hinrich defines that the elements of systems consist of Information/knowledge, communication, funding, and measurement systems. [11]

Information and knowledge have a very important role for the community and leadership. For the information society, information and knowledge is very useful to know how the program, so that people can make a decision to do something in support of the program's success. For the Government or the head of the organization, system can be used as a material of consideration in decision making, especially in programming, budgeting, facilitation, coaching, coordination and regulation. "How information, intelegence, and knowledge are used, distorted and transmitted has considerable significance for what we have just considered: how society assess its organizations"

George dan Jones explaines that communication is the sharing of information between two or more individuals or groups to gain general understanding [12]. While Greenberg dan Baron define communication as a process by which a person, group or organization transmit information to other persons, groups or other organizations [10]. Communication in an organization aims to improve coordination, information sharing and fulfillment of social needs. [12]

Communication is more important than ever in times of change. changes are most effective when a company communicates a rationale that balances the interests of various stakeholders (shareholders, employees, community, customers) rather than those of shareholders only [18]. Organizational Communication is increasing formal organizational communication with employees reduces uncertainty by lessening role ambiguity and role conflict [18]. Communication occurs when sustainability-related issues are conceived, defined, discussed, planned, initiated within and between organizations, modified, and, perhaps, terminated. It is present when various stakeholders encounter and react to the initiatives. [1]

Communication within the organization either among members or units can be either vertical or lateral and formal or informal. [6]

Coordination is needed in integrating and synchronizing the units within an organization, so it can support each other in achieving the goals that have been determined. [23]

Stonner defines coordination is the process of integration of objectives and activities of separate units within departments and functional areas within a company to achieve its goals efficiently. [23]

In the implementation and coordination [21] divide into two types, namely the coordination of vertical and horizontal coordination. Stonner suggests three approaches to implementing effective coordination: first basic management techniques are done through (a) Herarkhi managerial, (b) rules and procedures, (c) plans and goals; Both the increase in the potential for coordination is done through: (a) the vertical information system and (b) lateral relations; and third reduces the need for coordination, namely through the provision of backup resources and establish independent units.

The third element of system in the design of the proposed organization is system of funding [11]. Funding is an important elemen in running the program. No activity runs well without funding. The program can be funded by the member of organization or others.

Measurement is a basic undestanding of process or phenomenon that is being measured. We can not measure the elemen of systems in an organization if we don't know what is supposed to do, and how it is supposed to work. [3]

The performance of a System in an organization can be 
measured from the efficiency and effectiveness of a system in an organization. Effectiveness refers to both outcome and output measures, to talk about a program is talk about what impact it is having. [3]. So when we discuss the efectiveness of systems in an organization we will talk about the impact of the systems is having. Efficiency is measured by indentifying all of inputs used with producing a given services, such as salaries, overheads, materials, and estimated facilities cost. [3]

From the opinion of some experts it can be concluded that the systems in organizational design is the infrastructure to perform the process which comprises a collection of parts that are interconnected and interdependently incorporated. The mutual interactions are defined as rules and are designed to achieve the goal.

\subsection{Hyphotsis Frameworks}

Based on the theory described above the hypothesis framework of this research is as follows: Element System in organization of development programs for local food consisting of sub-systems information, communication, a funding, measures system in a program of activities that are mutually bound, integrated with one another and interacted reciprocity under policy in achieving optimum productivity and performance in order to achieve food security and sovereignty by developing local food.

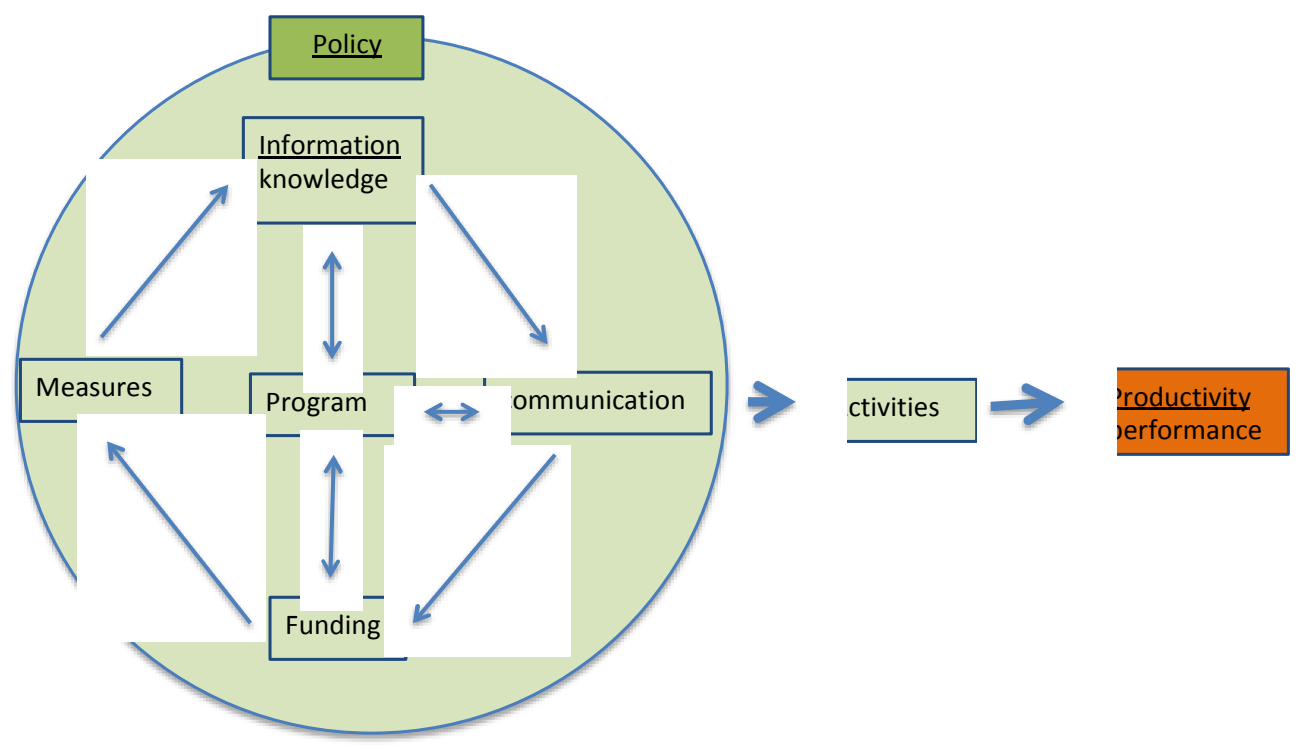

Figure 1. Hyphotsis Frameworks of a System in organisation of development program for local food in Trenggalek, East Java.

\section{Research Methods}

\subsection{The Object of Research}

The object of research was the element of systems in the organization of local food development program in the District of Trenggalek. The organizations involved were organizations from government, civil society, academia, and business support.

\subsection{Research Design}

The study used an exploratory approach (qualitative):'Explore a new topic, describe a social phenomenon, and explain why something accurs. The research goal was formulated more precise questions that future research can answer' [16]. This study sought to conduct in-depth exploration of the phenomenon of the elements of systems in the organization of local food development program of the research sites. With this qualitative approach researcher intended to develop the concept of thinking, understanding the patterns obtained from the exploration of observed phenomena of the whole process, individual and group research location.

The design of this study, researcher immediately saw and observed the objects of research and listened to any information submitted by the informant in an effort to obtain more objective data, factual, in-depth and thorough.

\subsection{Data}

The primary data were obtained through observation, interviews with informants involved in the development of local food program with personnel from relevant stakeholder organizations. Secondary data were obtained from written documents of the organizations involved in the development of local food in Trenggalek.

\subsection{The Research Informant}

Informants in this study were the stakeholders involved in the development of local food program both individuals and organizations in the government sector and local food developer's actor. Organizations involved were the Assistant Regional Secretariat for Economic Affairs; Department of Agriculture, Forestry and Agriculture; Department of Cooperatives, Industry, Trade, Mines and Energy; Food 
Security Office Trenggalek; District Planning and Development Board; and Cooperative.

\subsection{Research Proceedures}

The research was carried out through several stages: precourt stage and phase of field research to collect data through observation and interview continued with less editing of data reduction and data classification, data analysis and processing ends with the research reports. Before the implementation phase, research was begun with various activities such as administration to the technical preparations and the activities associated with the substance.

\subsection{Data Analyses}

Analysis of information was an effort to locate and systematically record the minutes of observation, interviews to improve the understanding of the cases studied. To improve the understanding of the analysis, and to find the meaning. Information of tangible words compiled into the expanded text. Material was obtained by analysing field notes. This proccess will encourage researcher to write field notes that were completed and detailed, because it was closely related to the analysis of the results of the collection of information process.

The process of qualitative analysis consisted of three lines of activities occurring simultaneously, namely the reduction, testing information and conclusion. [14] From the results of the analysis through the reduction process, test of information it will describes the conclusion and further formulation to design a model of element of systems in the local food developmen program. To ensure the validity and feasibility of the data being analysed was carried triangulation process.

Triangulation is a technique that utilizes data validity checking something else from outside the data for checking purposes or as a comparison to data [15]. To check the validity of this data was carried by triangulation 1) comparing the observed data with data from interviews, 2) comparing what is said the related informant, 3 ) compare the results of interviews with the contents of a document; Checking through triangulation process was conducted from the beginning of data collection to the implementation of data analysis and always be checked against the collected data.

\section{Discussion}

\subsection{The Element of Systems in the Organisation of Local Food Development Program}

The organizational design is the order of the whole process of work that resulted in the attachment of vision / mission, values / principles, strategies, goals, tactics, systems, structures, people, processes, culture and performance measures to achieve the required result in an operational context. [19]

Systems is one of important elemens in the food development organisation program in Indonesia. Systems: Information/knowledge, communication, funding, and measurement systems". [11]

Systems of local food development program is the infrastructure to carry out a process of providing information the program how to utilize local product by the organization involved, the government assist the access to get funding, how to manage, providing information management system and Information Technology [19]. Systems in organizations is closely related to processes from preparing, providing managing, actors and performance measures of the program.

In the organization of local food development programs in Trenggalek District which involves stakeholders with a centralized system under the coordination and responsibility of the Bupati as the government leader. Facilitation programs, guidance, regulations and policies are controlled by the Bupati, while technical facilitation is delegated to technical offices related to the program. While the decentralized system in obtaining and disseminating information, information and knowledge is carried out and the delegation of each stakeholder is in accordance with their respective roles, functions and competencies. Each stakeholder is characterized by differentiation and integration. In order to maintain unity among the parts that deferentiate and complete the entire form, each system has a reciprocal integration process. Each system requires differentiation to identify sub-units and integration to ensure that the system is not split into separate elements. [17]

The system in the organization of local food development programs in Trenggalek District shows the existence of linkages, coordination and integration among various elements of the government, the main actors of local food developers, academics and R \& D institutions, and supporting actors to the product users. Systems in the design of this organization include planning systems, funding systems, production systems, communication systems, coordination systems, facilitation systems, correctional systems and publications, guidance and extension systems, management systems, and development systems of all stakeholders involved in food development programs local.

Hinrich defines the system as an information / knowledge, communication, funding and measurement systems. From the opinion of some experts it can be concluded that the system in organizational design is the infrastructure to perform the process which comprises a collection of parts that are interconnected and interdependent that incorporates the interactions are defined as rules and are designed to achieve the goal. [11]

In the system of local food development program in Kabupaten Trenggalek there was an attachment, reciprocal integration ranging from planning, production to development through coordinated hierarchical level tools, direct supervision and the prevailing policies of each of the stakeholders who were bound together. Each stakeholder has a system in accordance with competence, roles and functions. This condition is in line with the opinions of Stanford. [19, 22, 17] 
From the results of the research on the system in local food development organization it was concluded that the success and continuity of the program is influenced by the involvement of all stakeholders through mutual systems in achieving goals which included information, communication, funding and results of measurement systems, planning systems, facilitation, guidance, management and development systems that are bound.

The system of design organization according to Stanford [19] covers the financial system, information management system and a system that is dependent on information technology. Systems in organizations closely related to processes, people, and performance measures [19]. System elements in the design of the organization by Hinrich" Systems: Information/knowledge, communication, funding, and measurement systems". [11].

Information and decision processes are the ways in which work gets done in organizations. There are three kinds of information and decision processes. They are the informal, or voluntary, kinds of processes that we used to refer to and now takes place over social networks. The second are business processe, and the third are management processes for allocating the scarce resources that are applied to the various opportunities facing the company. (9)

\subsection{Information System in the Organization of Local Food Developmet Program}

Information and knowledge have a very important role for the community and leadership. For the information society, information and knowledge is very useful to know how the program is, so that people can make a decision to do something in support of the program successfully. The Government or the head of the organization may use as consideration in decision-making, especially in the preparation of the program, facilitation, coaching, coordination and regulation.

"How information, intelegence, and knowledge are used, distorted and transmitted has considerable significance for what we have just considered: how society assess its organizations".

Food development programs in Trenggalek have a system how organizations obtain and disseminate information, information and knowledge. The system of information in local food development programs in Trenggalek at the beginning of the program runs very quickly and effectively so that local food development program relatively quick spread to the entire community locally and nationally with a centralized organization and decentralized of information systems in the local food development program in Trenggalek conveyed through electronic media, print media, presentations by the Local Government and each institution.

\subsection{Information in Centralized Systems}

Centralized systems are done and dealt with the leadership of the organization as a coordinator, responsible and decision makers in both the spread and receive information and knowledge, which is the Regent as head of government in charge of the development program of local food in Trenggalek, while technically deligated to agencies technical issues related to the program. The government has information that the system more bureaucratic and structured. The Government has developed an information system through institutions involved in food development program under the coordination of the Regent.

From the data collected showed that many direct centralized information systems delivered by the Head of District government. Direct public information capture it and immediately get involved so that the activity program quickly spread. The information submitted and carried out by those who have authority as a model to be more quickly accepted and followed by the community.

The policy of the Regent on information and knowledge related to local food development programs was conveyed through the Heads of Department and related agencies. They conduct cooperation and coordination with academia and $\mathrm{R}$ \& D, Ministry of Research and Technology, and the Ministry of Agriculture.

\subsection{Information in Decentralized Systems}

While the decentralized system, in obtaining and disseminating information and knowledge is done by delegating and decentralized to each stakeholder in accordance with the role, functions and competencies of each. In a decentralized system of government agencies as a facilitator, regulator and builder has happened distribution of roles and functions are decentralized to agencies in accordance with the relevant technical competence. Cooperatives, Industry, Trade and Mining Department in disseminating information, information and knowledge about food development programs associated with the industry together with the cooperative has conducted training, followed exhibitions and guided to the clusters, SMEs and cooperatives. The data from interviews with informants indicate that the information systems in organizations of local food development program in Trenggalek done centrally led by the regent, while the information systems that are technically and operationally done decentralized stakeholders of local food development program according to the role, duties, functions and competencies of each office based on delegation.

From the results of document data and interviews conducted by researchers with the informen about information, information and knowledge acquired for the stakeholders involved in the community, business, government and academia and R \& D shows that both hierarchy ie centralized and decentralized done in the local food development programs in Trenggalek.

\subsection{Communication in the Organization of Local Food Developmet Program}

The second system in the design of the organization stated Hinrichs is communication. [11] argues that communication 
is the sharing of information between two or more individuals or groups to gain a general understanding. While Greenberg and Baron defines communication as a process by which a person, group or organization transmit information to other persons, groups or other organizations communication system is the process of delivering and receiving information in formal and informal groups of an organization [10]. The communications system in food development programs conducted by government agencies and other stakeholders in the organization's developer program. At the beginning of the program implementation and dissemination to the public communication is initiated by the Regent. In food development programs in the District Tenggalek involving many stakeholders, it is in this program need the communication system of interlocking and integrated. In this food development program communication system includes a system of coordination, supervision, regulation and supervision so that a process of mutual interaction.

Communication in an organization aims to improve coordination, information sharing and fulfillment of social needs [11] According to Cook and Husnaker in the organization of communication between members or between units can be either vertically or horizontally 1 and formal or informal. [6]

In food development programs in Trenggalek communication process can occur vertically or horizontally and formally or informally depending on the circumstances. Communications also occur among individuals with individual, group by group, and also from individuals to groups and vice versa. Communication in local food development program going on between the government sector with local food developers' actor, or government to government, government by the people, the actors mocaf developers and communities as well as with academics. Vertical communication occurs between leaders and subordinates or vice versa. Communication from the head to the subordinate can include commands or instructions. Communication from subordinates to superiors can be in the form of a report. While the lateral or horizontal communication occurs on officials at the same level or between staff with staff in an organization. In general, in communications that are lateral or horizontal is a coordination meeting or synchronization. Communication can be formal generally occurs in formal organizations or government organizations, while informal communication is common in organizations. In a formal communication is typically less communicative whereas informal communication is usually more communicative. In organizations of local food development program in Trenggalek formal communication occurs in the government agencies, businesses and institutions. While non-formal communication occurs in non-governmental organizations such as farmers' groups, clusters, and cooperative. Based on documents, field observation and interviews with informants obtained a description that: the local food development programs in Trenggalek is very opened and smooth. Whereas local leaders can easily communicate with academics / researchers, farmers, businesses and communities. Regents invited the stakeholders directly to communicate with anyone else involved. Regent directly invite related agencies and give a verbal command, then the relevant agencies to plan and carry out the program and budget for each office. Government provide guidance and insight to the public. As a vehicle to promote local food development program, the Government has always actively participated in every exhibition program. The program of promotion and communication among agencies and stakeholders, developers' local food has a very positive interaction both regionally, nationally and internationally.

\subsection{Coordination System in the Organization of Local Food Developmet Program}

Coordinate systems in food development programs tailored to the development of policy mechanisms: a minimal basis in accordance with the development planning mechanisms ranging from Planning and Development Discussion in the District, the District continued to discuss the budget then submitted to Parliament and synchronized with the Central. Regional development program Assistant Secretary for Economic Affairs and Development, Economic Administration Section assisted the coordination of the agencies acted upon relevant agencies. Coordinate system development program of food with food diversification involves several related offices, namely the Department of Agriculture, Forestry and Agriculture, Department of Coopertave, Industry, Trade and Mining, Extension Agency and Regional Development Agency in the form of a team.

An organization is a social unit of people that is structured and managed to meet a need or to pursue collective goals. All organizations have a management structure that determines relationships between the different activities and the members and subdivides and assigns roles, responsibilities, and authority to carry out different tasks. The activities must then be coordinated. [4]

Coordination and synchronization in food development programs in Trenggalek indispensable. Stoner argues that coordination is needed in integrating and synchronizing the units within an organization, so it can support each other in achieving the goals that have been determined [23]. Stonner defines the coordination is the process of integration of objectives and activities of separate units within departments and functional areas within a company to achieve its goals efficiently [23]. In the implementation and coordination, Pierce Gardner divide into two types, namely the coordination of vertical and horizontal coordination. Stonner suggests three approaches to implementing effective coordination: first basic management techniques are done through (a) Herarkhi managerial, (b) rules and procedures, (c) plans and goals; Both the increase in the potential for coordination is done through: (a) the vertical information system and (b) horizontal relations; and third reduces the need for coordination, namely through the provision of backup resources and establish independent units. [21] 
In the organization of local food development programs need better internal coordination within and between the stake holders in order to achieve the success of the program. In this program strake holders are clustered into the government, the main actors of food developers, academia and $\mathrm{R} \& \mathrm{D}$ and supporting actor. Coordination within government stakeholders related to the program facilitation, coaching and regulations, particularly for the main actors of food developers and the community as a user. Coordination classified into vertical and horizontal coordination, internal and external. Coordination within the government is based on the rules outlined in legislation. Coordination could be in program planning, implementation and evaluation of programs. The planning of the program is done through a bottom-up, top down, the political and technocratic. The mechanism of coordination of the program begins with a program of development planning mechanisms ranging from the Discussion for synchronze planing and developing of sub-district, district and submitted to Parliament and synchronized with the center of the macro program. Coordination is not only done once or twice a year when preparing the budget and budget changes, but also coordination with the Provincial Government, and the Center for Private.

In planning the program of each government agency in Trenggalek is coordinated under the coordination of District Planning and Development Board, this coordination is horizontal coordination. Prior coordination at the level of departments within the agency to coordinate ranging from parts to be spliced official program and then coordination of their respective offices into local government level program. In the process of coordination in accordance with the working procedures and mechanisms of implementation of tasks related agencies of local food development programs, government agencies refer to current government regulations, based on official documents of local governments. In the Food Security program in the implementation of activities in general involve relevant institutions in the form of a team based on the type of activities. Agencies involved in the coordination of the food security program is the Office of Cooperative, Industry, Trade and Mining, The Ofice of Agriculture, Forestry and Plantation, Health Department, District Planning Development Board and Statistic Beareu, Inter-agency coordination in food development programs in Trenggalek is still not nurtured properly. Still there are overlapping programs due to lack of clarity of the duties of the institution builder in the central and regional agencies.

In the system of guidance and counselling, Extension Agency prepare and organize group together with Food Security Office and then follow conduct regular counseling. The implementation of the system development and food development in Trenggalek Food Security Office have training collaboration with Offices associated with collaboration between farmer groups, and processed food industry and facilitation of equipment for the success of the program. The Office of Cooperatives, Trade, Industry and
Mining in food development program, is more accountable system of facilitation, coaching, coordination and information of the main actors associated with the program developer of industry, trade, small and medium enterprises and cooperatives.

Facilitation system is conducted by the Office of Cooperatives, Trade, Industry and Mining is facilitated in the provision of equipment and infrastructure and coaching facilities in the form of processed food processing training. In addition to training and coaching small to medium businesses and facilitating industry in product marketing, facilitating the provision of facilities and infrastructure and the training is done in coordination with the cooperatives, clusters and SMEs. the Office of Cooperatives, Trade, Industry and Mining also needs financial aid system, facilitation, information and dissemination to small and medium enterprises in a program related to food development program.

\subsection{Funding System in the Organization of Local Food Developmet Program}

The third system element in the design of the proposed organization Hinrichs is the funding system [11]. The system of budgeting in the public sector is regulated through Budget System at the state and local level. The budgeting system of food development program activities in Trenggalek is submitted and programmed by related Office accordance with the duties and function to facilitate in the form of equipment, training and guidance. The system of budgeting is done through the relevant agencies. the government has budgeted for activities associated with the development program of food. Besides funding system in the development program of food in Trenggalek related to program development and production conducted actor premier developer, the government is also involving private investors. Based on the analysis of documents and interviews with informants it is obtained a description of the system that deals with systems other than those are delivered by Hinrichs. The IT systems is the planning system; process system activity; management system; system development and coaching. Planning and budgeting systems in government programs Trenggalek is coordinated by District Planning and Development Board accordance with their function. While the food system in the development program is coordinated by Assistant of Economic Sector and Development. Each agency has budgeted for local food development programs in accordance with their function and assignment

\subsection{Measurement Systems in the Organization of Local Food Developmet Program}

Measurement is a basic undestanding of process or phenomenon that is being measured. We can not measure the the system elemen in an organization if we don't know what is supposed to do, and how it is supposed to work. [3]

The performance of a system in an organization is the 
efficiency and effectiveness of a system in an organization. Effectiveness refers to both outcome and output measures, to talk about a program is talked about what impact it is having. [3]. So when we discuss the efectiveness of systems in an organization we will talk about the impact of the system is having. Efficiency is measured by indentifying all of inputs used with producing a given services, such as salaries, overheads, materials, and estimated facilities cost [3]. The effectiveness dan efficiency of system of the food development program organization can be measured from the the impact of the system having and the cost is expended.

The system in the local food develompent program runs effectively. At the beginning, the program runs effectively. The local food development program relatively quick spread to the entire community locally and nationally with a centralized organization and desntralized.

Organization of information systems in the Food development program in Trenggalek conveyed through electronic media, print media, presentations by the Local Government and each institution. Communication can be formally occurred in formal organizations or government organizations, while informal communication is commonly occurred in organizations that are familiar. In a formal communication is typically less communicative whereas informal communication is usually more communicative and effective.

The communication process can occur vertically or horizontally and formally or informally depending on the circumstances. Communications also occur among individuals with individual, group by group, and also from individuals to groups and vice versa.

Based on the implementation of system in the food development program organization shows efficiently.

\section{Conclussion}

This study could be concluded that the Element of Systems on Organisation of Local Food Development Program in the district of Trenggalek, East Java Province is

In general, the system prevailing in the organization of food development programs in Trenggalek is in line with the opinion of Boulding. [22]

The whole stakeholders are integrated with each other and interacted reciprocity through herarkhi levels, their direct supervision and there is a policy.

The information and knowledge acquired for the stakeholders those are involved in the community, business, government and academia and $\mathrm{R} \& \mathrm{D}$ shows that both hierarchy either centralized or decentralized are done in the local food development programs in Trenggalek.

Formal Communication generally occurs in formal organizations or government organizations, while informal communication is commonly in informal organizations. In a formal communication is typically less communicative whereas informal communication is usually more communicative.

The organization of local food development programs need better internal coordination within and between the stake holders in order to achieve the success of the program.

The system of budgeting is done through the relevant agencies. the government has budgeted for activities associated with the development program of food.

Besides funding system in the development program of food in Trenggalek related to program development and production conducted actor premier developer, the government also involving private investors.

The element of systems in the organization of local food development program in Trenggalek include system of planning, systems of funding, systems of production, systems of communications, the systems of coordination, a system of facilitation, and systems of publication, the systems of guidance and extension, system of management, and system of development. Each stakeholder has a system in accordance with the competence, roles and functions. This condition is in line with the opinion of Stanford [19,22], and Robin. [17]

The element of systems in the organization of local food development programs are mutually bound, integrated with one another and interacted reciprocity under the policy made by District Government.

\section{Acknowledgements}

I would like to thank my colleagues who has assisted me to finish this study and the rector and staffs of the University of Pembanunan Nasional Veteran Jakarta. for their support.

\section{References}

[1] Allen, Myria, (2016), Strategic Communication for Sustainable Organizations Theory and Practice, Switzerland: Springer International Publishing.

[2] Alvesson, Mats and Stefan Sveningsson (2016), Changing Organizational Culture, New York: Routledge.

[3] Berman, Evan M. Performance and Productivity in Public and Non Profit Organizations, New York: M. E Sharpe.

[4] Burton, Richard M. et.al (2006,) Organization Design - The evolving state - of -the-art, USA: Springer.

[5] Christensen Tom, Lagreid Per, Roness. Paul G, and Rovik. Kjell Arne. (2007) Orgaization Theory and the Public Sector. London: Routledge Taylor \& Francis Group.

[6] Cook, Curtis W and Hunsahar, Pilip, 2001, Management and Organization Behaviour, Newyork: McGraw-Hill Higher Education.

[7] Daft, Richard L, (2008). Organization Theory and Design, USA: SOUTH WESTERN Cengage Learning.

[8] Denhardt, Janet V and Denhardt Robert B. (2007). The New Public Service, expanded edition, New York: M. E Sharpe. Inc.

[9] Galbraith, Jay R. (2014), Designing Organizations: Strategy, Structure, and Process, San Francisco: Jossey-Bass A Wiley. 
[10] Greenberg Jerald \& Robert A. Baron, (2003), Behavior in Organisations, New Jersey: Prentice Hall International, Inc.

[11] Hinrichs, Gina, (2009), Organic Design Organization, Organizational Development Practitioner, Vol 41 No 4.

[12] Jones, Gareth, (2010). Organizational Theory, Design and Change, New Jersey: Pearson Education, Inc.

[13] Laurie J. Mullins, (2016), Management \& Organisational Behaviour, Great Britain: Pearson.

[14] Miles, Matthew B and Huberman A Michael. (2009) Analisa Data Kualitatif, Terjemahan Tjetjep Rohendi Rohidi. Jakarta: UI Press.

[15] Moleong, Lexy J, 2010. Metodologi Penelitian Kualitatif (edisi Revisi) Bandung: PT Remaja Rosdakarya.

[16] "Neuman, W. Lawrence, (1997). "Social Research Methods: Qualitative and Quantitative Approach", USA: Allyn and Bacon, Incorparated.

[17] Robbins Stephen P.'and Judge Timothy A, (2007). Organizational Behaviour, New jersey: Pearson Education. Inc.
[18] Robbins Stephen P.'and Judge Timothy A, (2017). Organizational Behaviour, New jersey: Pearson Education. Inc.

[19] Stanford Naomi, (2005). Organization Design: The Collaborative Approach. Great Britain: Elsevier Butterworth Heinemann publicationsprofile Books Ltd.

[20] Dignum, Virginia; Pablo Noriega Murat Sensoy - Jaime Simão Sichman (Eds.) (2015) Coordination, Organizations, Institutions, and Normes in Agent Systems XI, Argentina: Coin.

[21] Pierce Jhon I, Gardner Donald \& Dunham Randall B, 2002, Management and Organizational behavior an integrated Perspective, Ohio: South Western Thomson Learning.

[22] Shafritz, J., \& Ott, J. S. (2001). Classics of organization theory (5th ed.). Fort Worth, TX: Harcourt College Publishers.

[23] Stoner, J. A. F.; Freeman, R. E. and Gilbert Jr., D. R. (2007), Management, Prentice Hall of India: Pvt. Ltd., New Delhi. 